EPiC Series in Education Science
Volume 2, 2019, Pages 28-39
$\begin{gathered}\text { Proceedings of Learning Innova- } \\ \text { tions and Quality (LINQ) 2019 }\end{gathered}$

\title{
Participatory model for identifying and measuring teachers' competences for open and Inquiry-based learning in STEM: field experience
}

\author{
Eliza Stefanova $^{1}$, Nikolina Nikolova ${ }^{1}$, Temenuzhka Zafirova-Malcheva $^{1}$, \\ Pencho Mihnev ${ }^{1}$, Atanas Georgiev ${ }^{1}$, Albena Antonova ${ }^{1}$ \\ ${ }^{1}$ Faculty of Mathematics and Informatics, Sofia University, Sofia, Bulgaria \\ eliza@fmi.uni-sofia.bg, nnikolova@fmi.uni-sofia.bg, \\ tzafirova@fmi.uni-sofia.bg, pmihnev@fmi.uni-sofia.bg, atanas@fmi.uni- \\ sofia.bg, a_antonovalfmi.uni-sofia.bg
}

\begin{abstract}
Wider adoption of open educational practices and inquiry-based learning (IBL) methods in schools brings many challenges for teacher training especially in the field of STEM. Young teachers have to acquire a large number of competences - knowledge, skills, and attitudes, in order to be able to design and implement innovative and enriching open learning experiences in STEM. Besides STEM expertise, teachers have to demonstrate autonomy, creativity, mastery of innovative learning methods, teamworking and leadership skills. This makes defining, teaching and measuring teachers' competences for applying IBL training on practice a complex and demanding task. The present research aims to investigate and determine a relevant and practice-oriented STEM teacher competence framework. The participatory field experiment step on the previous outcomes of the IBL project ELITe (Enhancing Learning In Teaching via e-inquiries)* and brought together STEM teachers, teacher trainers and researchers. This way, authors succeeded to identify three main groups of practice-oriented competences, including two levels of 44 sub-competences. These competences have been addressed within a competence-based pilot course in Moodle referring to IBL activities that can measure and improve STEM teachers' competence. The outcomes of this field experience demonstrate that participatory methods for teachers' training bring additional understanding, motivation and clarification and readiness for adoption of innovative open learning practices in the classroom.
\end{abstract}

\footnotetext{
* The project ELITe (Enhancing Learning in Teaching via e-inquiries) is Erasmus+ project, financed by EU. More information is available on http://www.learning-in-teaching.eu/index.php/en/;
} 


\section{Introduction}

Open learning approaches necessitate new methods and competences for teaching. During the last years, the attention on open and inquiry-based learning (IBL) methods increased, due to their efficiency and positive learning outcomes, specifically in the field of science, technology, engineering and mathematics (STEM). However, in order to successfully implement an IBL scenario in class, teachers have to shift from traditional lecturing models to collaborative, cooperative, open-ended and less structured learning models, empowering students to take the role of researchers and scientists and encouraging them to build new knowledge and skills from first-hand experiences, reflections and insights (Nikolova et al., 2018). Especially for designing, practising and improving the quality of open learning, teachers have to master extended professional competences, allowing them to successfully plan, implement and facilitate engaging and motivating open-ended learning experiences. Furthermore, competency-based education (CBE), along with other related terms such as performance-based, proficiency-based, mastery-based learning have long traditions in teacher training and education (Tuxworth, 2005). As stated in Twyman (2014), competency-based education is personalized learning approach that respects individual learner differences and supports them in the mastery of standards and aligned competencies. Among the main tenets of competency-based learning is the mastery of competencies that reflect explicit, measurable and transferable learning objectives. More specifically, the learning outcomes of the competency-based learning take into account on one side application and creation of knowledge, and on the other side emphasize on development of important skills, attitudes and dispositions. Even more, competency-based learning ultimately relies on measurable assessment and every competency should be described unambiguously and subsequently measured (Voorhees, 2001). The meaningful CBE assessment, often embedded throughout teaching and learning is used to continuously inform and reflect learning progress. The adoption of new instruction technologies enables teachers and learners to make the assessment, self-assessment and reflection feasible, scalable, actionable, and transparent (Twyman, 2014). This makes competency-based education appropriate for teacher training, especially in the field of open learning and IBL.

Taking into account the needs to better prepare STEM teachers and teacher trainers for open and IBL learning approaches, the present research aims to investigate and determine a relevant and practiceoriented STEM teacher competence framework. By stepping on preliminary research (and ELITe' project outcomes $^{\dagger}$ ) and involving STEM teachers, teacher trainers and researchers, the authors designed and implemented a participatory field experiment. This way, they identified three main groups of IBLrelated and practice-oriented teacher competences, including two levels of 44 sub-competences. This competence framework has been implemented within a Moodle-based e-learning environment and served as a reference for developing different learning activities within a pilot Moodle course for STEM teachers' competence development. By assigning cross-competences for each course activity and covering all relevant competence framework elements, authors propose a methodology for e-learning course design for the development of IBL competence-based STEM teacher training.

The paper starts with a short overview of the main European and national policy context, determining the role of competence-based learning and IBL for STEM and life-long learning. Then it identifies the needs of defining teacher-focused IBL competence framework, along with appropriate methods for competence measurement. Next, the methodology, the context and the design of the field experiment are presented, following the main outputs and policy recommendations of the Erasmus+ project ELITe. The main section presents the participatory design of the field experiment, the competence framework and the competence-based training activities. By bringing together different participants in the teacher training process and STEM teachers with experience in IBL, the paper's authors succeeded to collect meaningful qualitative and quantitative data, insights, and

\footnotetext{
${ }^{\dagger}$ ELITe (Enhancing Learning in Teaching via e-inquiries) is Erasmus+ project, financed by EU. More information is available on http://www.learning-in-teaching.eu/index.php/en/;
} 
recommendations for defining relevant and practice-oriented competences. In the discussion section, there are defined the next steps and furthers activities for validating the competence-based framework. In the end, the paper highlights the advantages and perspectives for adopting an IBL competence-based learning framework for teacher training, supporting innovative learning experiences implementation.

\section{Background}

Digital transformation leads to rising demand for better preparing skilful and competent workforce for the new digital economy. This reflects the changing needs and requirements on European and national level, determining the general context for competence-based learning, adoption of open learning approaches and relevant teacher competences. Therefore, in the following sections are outlined the main policy requirements, circumstances and characteristics for defining the new set of teacher competences.

\subsection{The competence-based learning in European and national context}

During the last years, the European Commission (EC) worked actively with the EU Member States in order to identify and adopt policies and measures to develop key competences, necessary for guarantying and facilitating lifelong learning. As a result, in May 2018, The Council of the European Union adopted Recommendations on key competences for lifelong learning, proposed by the EC (Council of the European Union, 2018). As the document says, key competences include "knowledge, skills, and attitudes needed by all for personal fulfilment and development, employability, social inclusion and active citizenship." (ibid., p. 1). Eight such competencies have been identified, as follows: Literacy competence; Multilingual competence; Mathematical competence and competence in science, technology and engineering; Digital competence; Personal, social and learning to learn competence; Citizenship competence; Entrepreneurship competence; Cultural awareness and expression competence. As it was said by the EC, "The Council Recommendation provides a common European reference framework on key competences for policymakers, education and training providers, social partners and learners themselves. It also presents successful ways to promote competence development through innovative learning approaches, assessment methods and support for educational staff." Lately, in March 2019 the European Commission published the document "Key competences for lifelong learning" (European Commission, 2019), where all the eight key competences were explained, broken down to their constituent essential ingredients - knowledge, skills, and attitudes, which were described in detail. As it was said in this document, "All key competences are considered equally important and aspects essential to one domain will support competence development in another." (ibid., p. 5). It is important to say, that the third key competence - "Mathematical competence and competence in science, technology and engineering", directly refers to the development of Inquiry-based learning (IBL) skills for the purposes of the whole lifelong learning (ibid., p. 9). The fourth and fifth key competences - the Digital competence, and the Personal, social and learning to learn competence, also fully support and participates in the development of IBL knowledge, skills, and attitudes in the domain of STEM learning (ibid., pp. 10-11).

Based on the collaborative work of the EC with the Member States, the Bulgarian Government, and particularly the Ministry of Education and Science (MES) of Bulgaria, actively worked during the last years to develop, deploy and integrate the key competence framework for lifelong learning in the corresponding documents, and in education in the country in general, and more specifically - for the

\footnotetext{
\$ttps://ec.europa.eu/education/education-in-the-eu/council-recommendation-on-key-competences-for-lifelonglearning en
} 
preparation and work of Bulgarian teachers, including STEM teachers (e.g. Ministry of Education and Science, Republic of Bulgaria, 2015, 2016a, 2016b).

\subsection{The competence-based learning in IBL}

The raising need to identify the framework of teacher' competences, necessary for the adoption of IBL methods in class has been addressed on numerous instances during the implementation of the Erasmus+ project ELITe. The project ELITe's main objective was to support STEM teachers to develop knowledge, skills and attitudes so that they can effectively take the role of lifelong learners, facilitators of students' learning and members of educational communities. More specifically, the main outputs of the project are policy recommendations, pilots and best practices of IBL courses, teacher' handouts and tools for implementing active IBL learning scenarios and guidelines (ELITe, IO1-IO10) $)^{\S}$. Furthermore, most of the ELITe's outputs have been widely discussed and validated through participatory methods, bringing together all relevant stakeholders such as policymakers, teacher trainers, teachers and researchers.

Within the ELITe project activities, three key dimensions of (STEM) teachers' competences have been investigated and identified in the key Bulgarian policy documents: knowledge and understanding; skills; and dispositions (Nikolova, N. et al., 2017).

- The identified key components of Knowledge and understanding included, among others, the deep knowledge of the subject matter (the content), the knowledge in the domain of inclusive education; ICT in education, innovative teaching methods, evaluation and assessment methodologies.

- The identified key component of Skills included academic and pedagogical skills, communicative skills, team working skills, collaborative skills (including with stakeholders), administrative skills, research skills.

- The identified key components of disposition, beliefs, and attitudes included a commitment to promoting learning to all learners, positive attitudes to the needed change, flexibility, ongoing learning and professional improvement, including study and research.

By determining and eliciting the explicit and implicit requirements for STEM teachers and teacher trainers' competences within national documents, the ELITe project participants performed comparative cross-country analysis and insights, proposing a set of national policy recommendations (Nikolova, N. et al., 2017). This set of IBL teachers' competences has been further evaluated, ranked and analysed through a number of ELITe teacher pilots and teacher-training workshops (as for example in Peltekova et al., (2019), Nikolova \& Stefanova (2019), Stefanova \& Nikolova (2019), Stefanova et al., (2019)). At the end of the project, project partners brought together teachers, teacher trainers, researchers and policy representatives in a participatory validation event. There, through a set of participatory activities, event participants provided quantitative and qualitative feedback for relevant IBL competence framework. There, Bulgarian participants highlighted that among the main challenges for IBL wider implementation are on one hand the lack of specific teachers' competences for design, logistics, and orchestration of an IBL research process and, on the other hand, the lack of assessment criteria and metrics to measure the different competency groups of STEM teacher competences. For example, the analysis of the Bulgarian validation workshop clearly outlined the needs to further develop: basic digital competencies for STEM teachers, competencies for open learning and IBL methods implementation, competencies for negotiations and further professional and transversal skills and attitude and others (ELITe, IO8, Nikolova et al, 2019).

\footnotetext{
$\S$ The ELITe Intelectual Outputs (IO), IO1-IO10, are available on: http://www.learning-inteaching.eu/index.php/en/intellectual-outputs;
} 


\subsection{The methodology and design of participatory field experience}

The methodology and design of the field experiment included the following steps. First, in the preparatory phase, it outlined the explicit and implicit requirements for STEM teacher competences within the regulatory framework and official policy documents, available as an output of the ELITe project (ELITe, IO1) and summarized in (Nikolova, N. et al., 2017). Then, these competences have been ranked, evaluated and validated by teachers, teacher trainers and stakeholders, determining their relevance for IBL training via self-assessment forms (ELITe, IO8, Nikolova et al., 2019). The analysis of the outcomes allowed to identify those key groups of competences, required for further IBL implementation on practice. This ensured, that all identified components of the three key dimensions of teachers' competences are further used in the process of the development of STEM teacher competences and their measurement and are laid down in the foundation of the field experience.

The main part of the participatory field experiment brought together different stakeholders, allowing them to determine the IBL teachers' competence framework, along with relevant criteria for competence measuring and assessment. By participatory activities, the key stakeholders personally engaged, sharing their own experience and understanding of the IBL competence assessment and validation. Following their recommendations, the selected competences have been assigned to specific learning activities and artefacts, serving as a base for competence-based teacher training course in the e-learning platform Moodle. On the next stage, all these competences will be validated and measured.

The field experiment was implemented as a participatory workshop, taking into account that participatory methods provide meaningful and productive co-creation interactions, bringing together various stakeholders and end-users (Shuler \& Namioka, 1993). Unlike the user-centred design, where the focus is on the "thing" (outcome, artefact), the participatory design shifts its focus on the design processes (as in co-design and design-based research), integrating stakeholders through a variety of methods like interviews, observations or design activities (Muller \& Kuhn, 1993). Furthermore, the participatory framework recommends to use participatory tools and techniques (such as observations, interviews and design activities) in combination, and the ideal situation is to create a workshop (Sanders et al., 2010). This way, the participatory field experiment was designed as a participatory workshop, bringing together relevant stakeholders and involving them in three models of interaction: making (tangible things), telling (talking, explaining, reflecting), and enacting (acting, enacting, and playing).

\section{Description of the participatory field experiment}

Following the determined field experiment methodology design, the participatory experiment held part within a group workshop, bringing together 18 participants: STEM teachers, STEM teachers' trainers and researchers. To identify the scope of the IBL competence framework, all participants received initial instructions and handouts with initially defined set of competences, based on the outcomes of policy documents analysis (Nikolova, N. et al., 2017), validated during the ELITe Multiplier event (ELITe, IO10). Then, the participants split into three sub-groups, exploring three main competence dimensions: subject-related competences, IBL orchestration competences and methodology-related competences. All sub-groups included the following participants: experienced in IBL methodology teachers, teacher's trainers, researchers, involved in ELITe project activities and ICT (Moodle) experts. By exploring participatory methods such as interviews and observations, the participants in the sub-groups determined the key relevant sub-competences. For example, the first subgroup outlined the IBL competences for adopting appropriate teaching and learning methodologies (teaching "How"). The second group identified the competences for process orchestration, taking into account IBL and open learning planning and implementation, including leadership skills, teamwork, project management and others. The third group was focused on the main IBL teachers' competences, concerning subject-related knowledge, skills and attitudes, focusing on mastering the STEM learning 
material (teaching "What"). This way, by exploring personal IBL experiences, observing teachers' artefacts, and commenting their reflections and insights, lessons' learned, personal stories and good practices, all participants succeeded to determine the key dimensions of the IBL competence framework (Figure 1). Furthermore, by gaining a better understanding of the challenges for IBL scenarios practical implementation and real-life teachers' feedback, workshop participants determined different criteria for competence assessment and measurement.

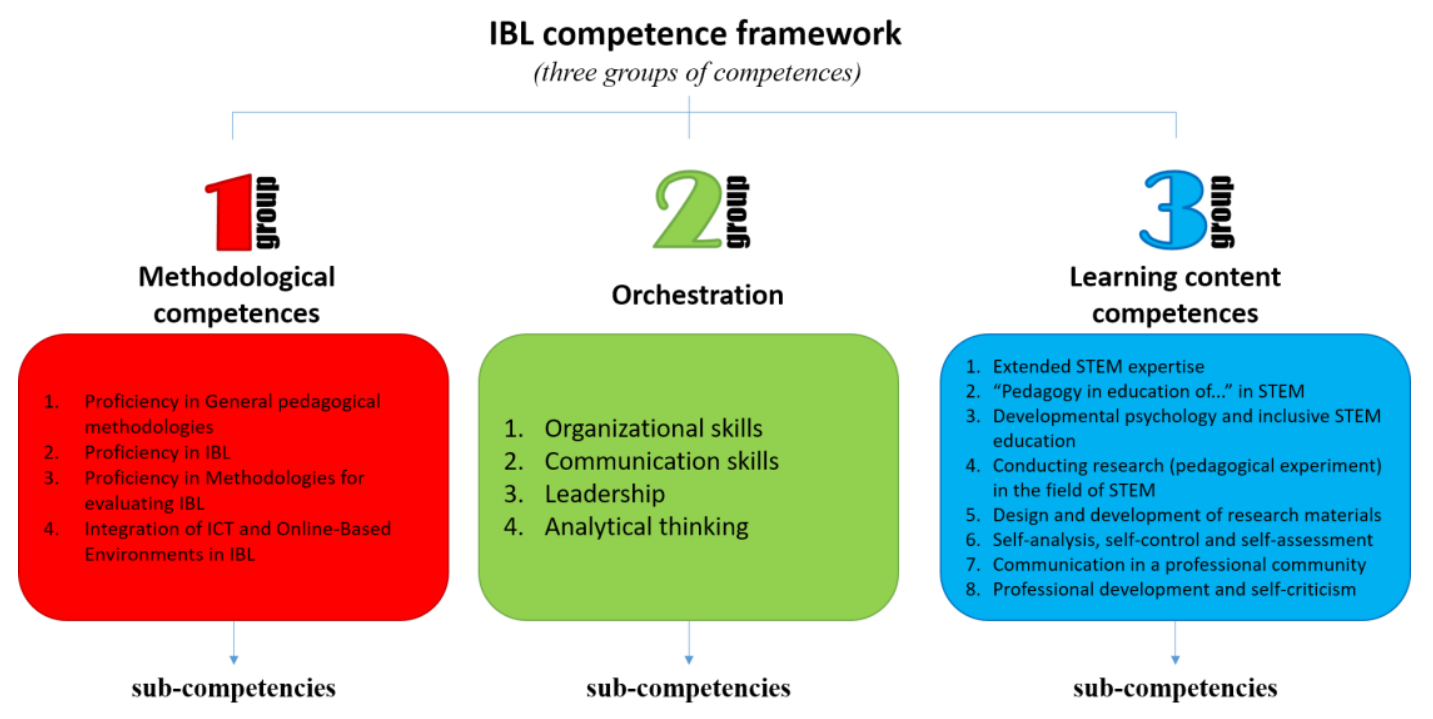

Figure 1. Competence framework structure and main competence dimensions.

\subsection{The Competence Framework}

As already outlined, the participants of the field experiment determined the IBL teacher 's competence framework by reviewing and completing the ELITe outcomes for IBL competences and by reflecting the insights, teacher's feedback and lessons learned, discussed during the participatory workshop. This way, they determined the main competence levels and sub-levels, taking into account how to measure all relevant competences and sub-competences on practice. In table 1 they are defined as the main competencies and sub-competencies of the IBL competence framework.

\begin{tabular}{lcl}
\hline Competencies & Sub-competencies \\
\hline 1.1 Proficiency in General & 1.1 .1 & Extended pedagogical knowledge \\
pedagogy & 1.1 .2 & Transferable Skills \\
& 1.1 .3 & Mastery in managing students and groups \\
& $1.1 .4 \quad$ Positive attitude for development of pedagogical \\
knowledge and skills & \\
& $1.2 .1 \quad$ Pedagogical knowledge about IBL methodologies \\
& 1.2 .2 & IBL planning skills \\
1.2 Proficiency in IBL & $1.2 .3 \quad$ Conducting IBL activities \\
& $1.2 .5 \quad$ IBL orchestration \\
& activities
\end{tabular}




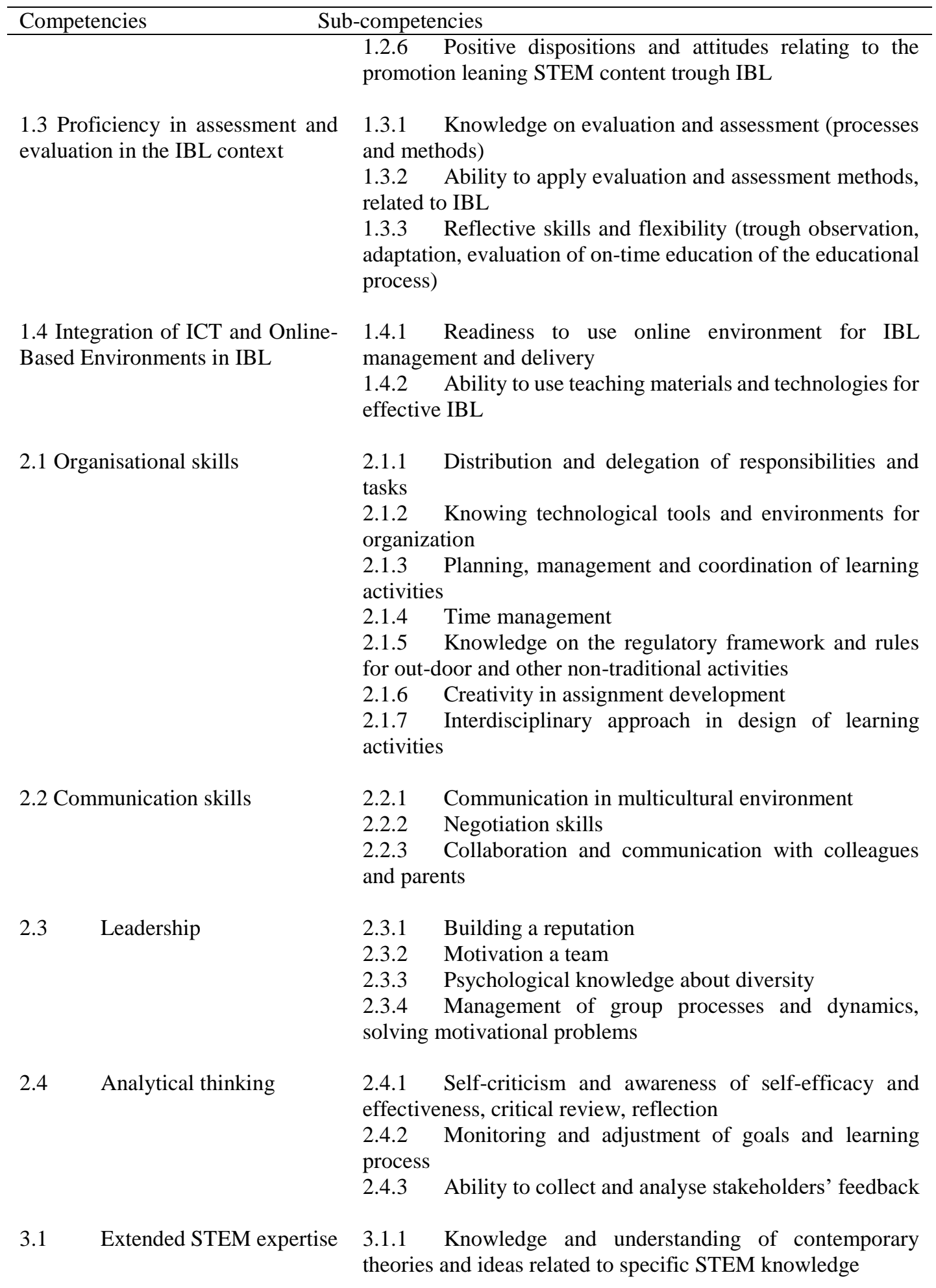




\begin{tabular}{|c|c|}
\hline Competencies & -competencies \\
\hline 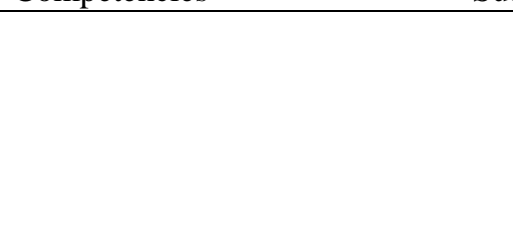 & $\begin{array}{l}\text { 3.1.2 Ability to apply basic experimental techniques in } \\
\text { science education } \\
3.1 .3 \text { Knowledge on basic scientific methods and main } \\
\text { points in the development of natural sciences } \\
\text { 3.1.4 Understanding and application in education of the } \\
\text { relationships between different sciences. }\end{array}$ \\
\hline 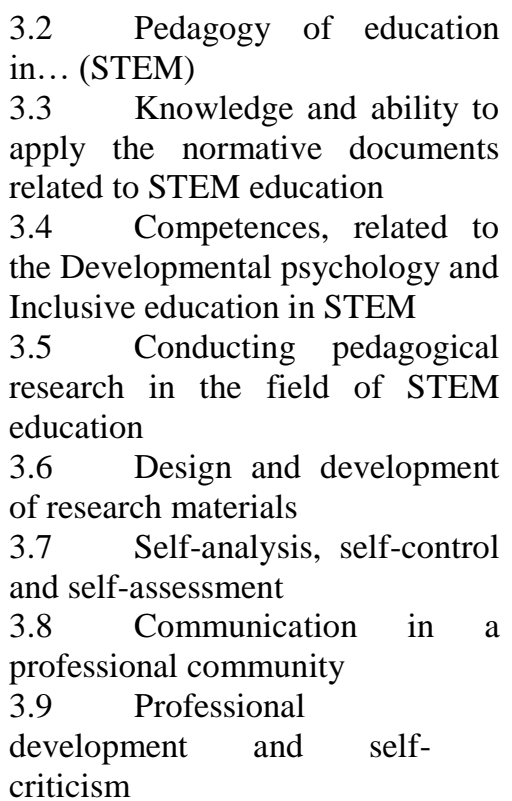 & \\
\hline
\end{tabular}

Table 1: Competence framework

\subsection{The Competence-based blended learning course}

Based on the developed competence framework (table 1), the participants in the workshop determined the blended learning teachers' training course: "Adoption of Inquiry-based learning methods for STEM in secondary schools". Exploring the competence-based functionality of the elearning platform Moodle, the authors defined specific online and blended learning course activities. This is how the determined competence framework (table 1) has been formalized and structured within a competence-based course in the e-learning platform Moodle. This way, the course activities have been set as competence-based blended learning tasks, completed upon achievement of specific evidence and provision of artefacts. Furthermore, there are outlined three learning paths, and course participants can choose and take part in one or all three learning cohorts. The learning paths, synchronized with the learning cohorts are designed to cover all elements of identified groups of STEM teachers' competences:

(1) Methodologies for Inquiry-based learning (IBL IN STEM-EDUCATION);

(2) IBL Orchestration (IBL IN STEM-EDUCATION);

(3) STEM Curriculum and learning content (IBL IN STEM-EDUCATION);

Therefore, the Moodle-based blended learning course covered all learning activities, evidence and assessment models for measuring teachers' competences and teachers' progress in mastering IBL 
competences in practice. Furthermore, due to the detailed competence framework, some of the competences do not need specific learning evidence and can be marked as acquired automatically, following acquiring the respective sub-competences.

To ensure that the different competences are acquired, eleven different activities were designed, each corresponding to several different competences within the framework (Table 2).

\begin{tabular}{|c|c|}
\hline \multicolumn{2}{|c|}{ Type of learning activity, evidences } \\
\hline D1. Define an IBL problem in STEM & Open assignment, documents \\
\hline D2. Propose an IBL implementation plan in STEM & $\begin{array}{l}\text { Open assignment, available } \\
\text { implementation templates }\end{array}$ \\
\hline D3. Assessment methods & Open assignment, enumeration \\
\hline D4. Propose assessment methodology & Open assignment \\
\hline $\begin{array}{l}\text { D5. Team work, organisation and tasks } \\
\text { distribution }\end{array}$ & Open assignment, documents, templates \\
\hline D6. Work-breakdown structure & Open assignment, ICT tools screenshots \\
\hline D7. IBL training implementation & Open assignment, documentation \\
\hline D8. Reflection & Open assignment, video \\
\hline D9. Exploration of STEM teaching documentation & Learning resources, documentation \\
\hline $\begin{array}{l}\text { D10. Exploration of "Ordinance on inclusive } \\
\text { education" }\end{array}$ & Learning resources, documentation \\
\hline D11. Lesson on inclusive education & Lesson, resources and quizzes \\
\hline Additional reading materials & $\begin{array}{l}\text { Study materials on IBL, digital IBL } \\
\text { instruments }\end{array}$ \\
\hline
\end{tabular}

Table 2: Online course activities;

The links between an activity and certain competences are based on the way in which the activity is designed, as well as on the areas of knowledge, skills and dispositions / attitudes that are required for its implementation. For example the first activity, (Table 2, D1) is related to definition of research problem in the field of STEM. The research problem should require the application of interdisciplinary knowledge and skills in the field of STEM discipline and to be motivated for learners. In order to carry out this activity, the teachers must possess certain competencies from each of the three groups in the competency framework. Figure 2 shows the relations between this activity and different subcompetencies from the competence framework. 


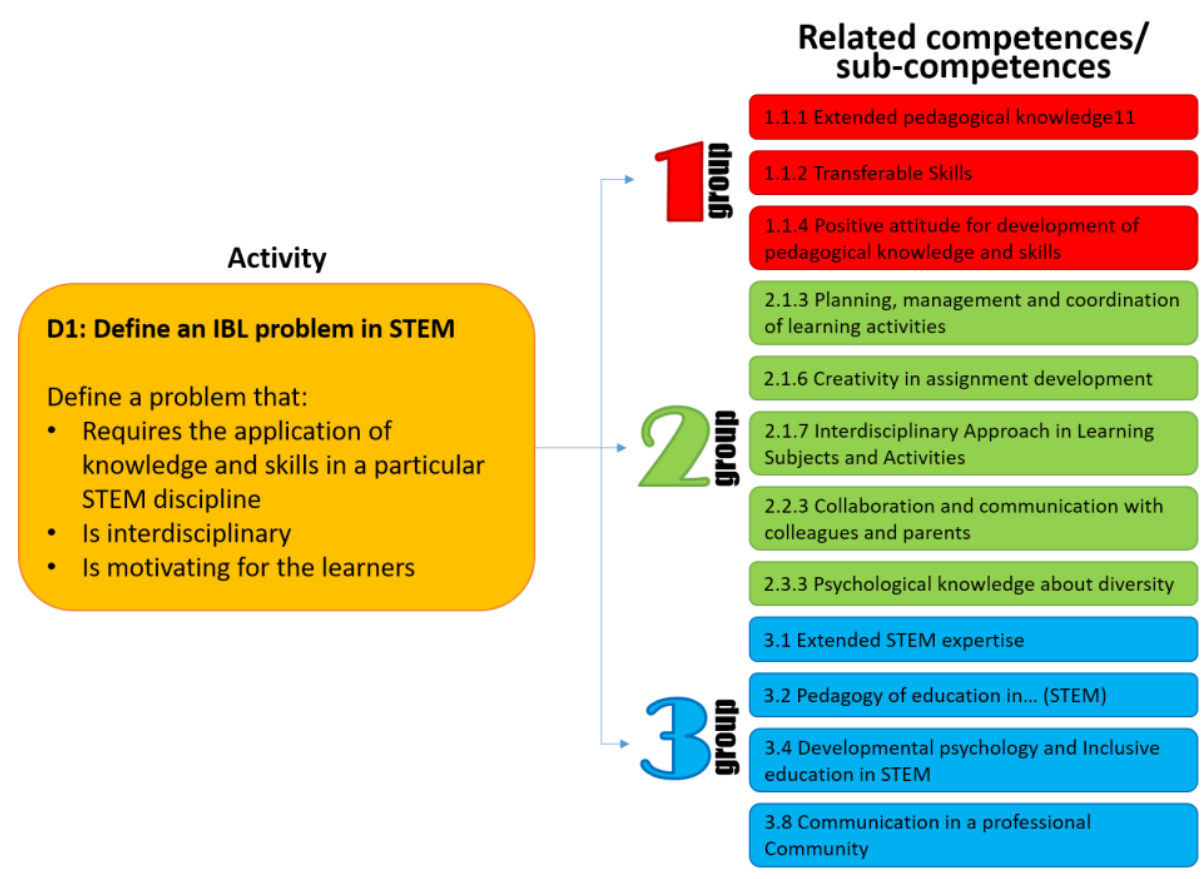

Figure 2. Activity D1 and related competences and sub-competences;

Figure 3 presents the activities listed above and their relations to particular sub-competencies from the competence framework. The numbering of the competency framework presented in the Table 1 was used to represent the sub-competencies in Figure 3.

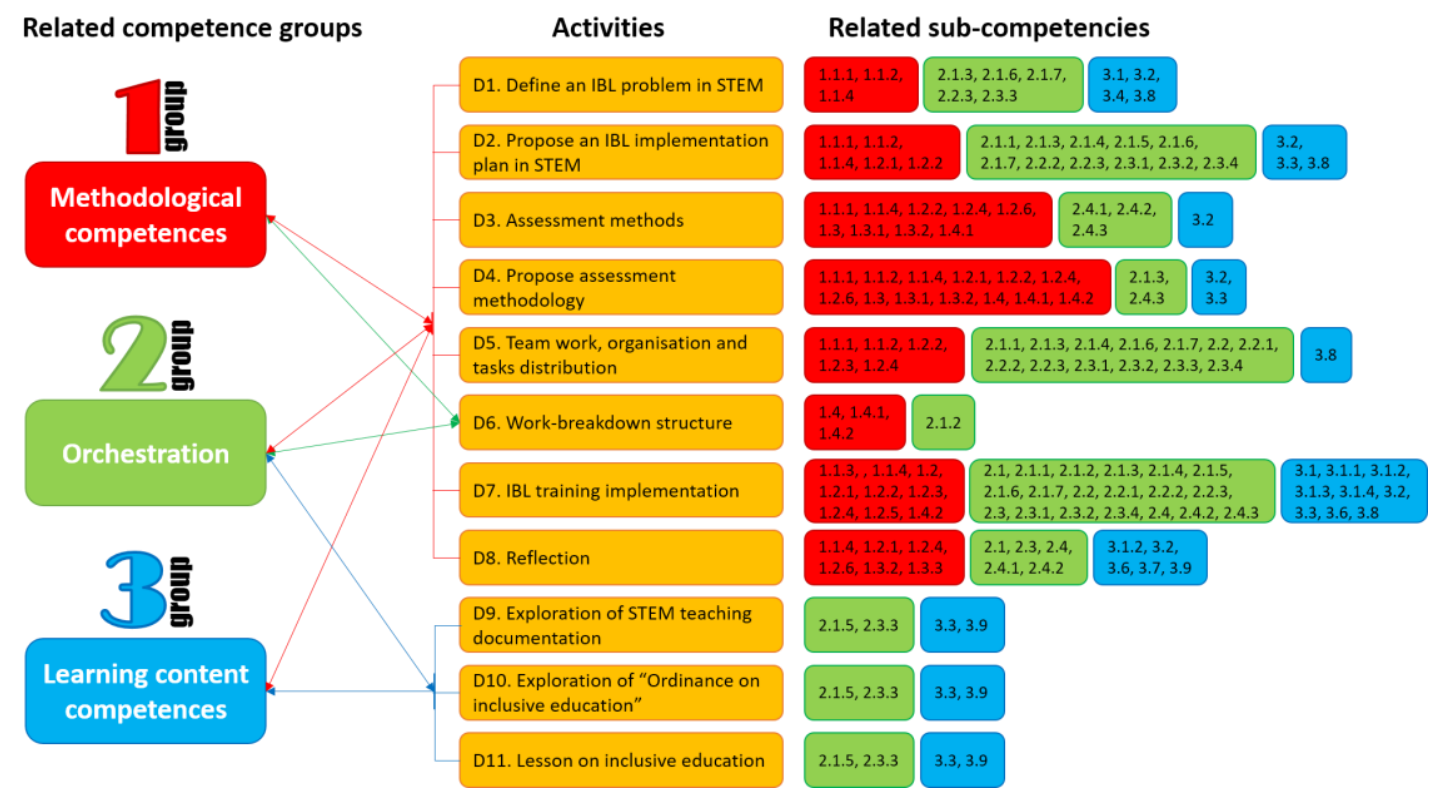

Figure 3 Relations: competence groups - activities - sub-competencies 


\section{Discussion}

The participatory field experiment provided valuable input for setting relevant competence framework for IBL practical teacher training. This way, to organize a competence-based IBL teachers' training, course designers have to consider that each course activity involves mastering of numerous competences and sub-competences, referring to specific theoretical knowledge, practical skills and personal attitude. On the other hand, completion of each learning activity leads to evidence and learning artefacts, enabling measuring and assessment of the level of competence mastering. Not last, using learning tools and e-learning platforms, supporting competence-based education, such as Moodle, allow course designers to automate competence-based learning processes, combining different methods such as self-evaluation, automatic evaluation and evaluation by teachers' trainer.

Even if the pilot testing of the competence framework and competence-based learning course is not yet finished, the proposed framework is flexible and allows further adjustments and modifications. After pilot completion, the authors will be able to further precise:

- How easy and convenient is it for the trainees to understand, reflect and monitor their own development of specific competencies.

- How reliable are the results and how they relate to the participants' self-assessment or their employers' competency assessment methods and tools.

- Whether such a method will be able to validate the achievements of the teachers, obtained through non-formal learning - such as participation in professional communities, conferences, self-study, experience and experiments within their own classroom.

\section{Conclusions and future work}

The outcomes of the participatory workshop, described in the present research, demonstrate that the process of the teachers' competence development is convergent, starting from the normative documents and ending up with specific pedagogical experience, documented as artefacts and evidence within the e-learning platform. Furthermore, the proposed competence framework is adjustable, flexible and adaptable. Using specialized e-learning tools and platforms, supporting CBE, allow course designers to flexibly adapt and rapidly change competences or learning activities, to further adapt and precise specific IBL dimensions and learning outcomes. Even more, a competence-based e-course provides better visibility and clear evidence for competence mastering, simplifying the complex assessment process and providing activities, relevant to the learner's personal style and learning objectives.

\section{Acknowledgments}

The research in this paper is partially supported by the Bulgarian Ministry of Education and Science under the National Research Programme "Young scientists and postdoctoral students" approved by DCM \# 577/17.08.2018, by the National Scientific Program "Information and Communication Technologies in Science, Education and Security" (ICT in SES) financed by the Bulgarian Ministry of Education and Science, and by the Sofia University "St. Kliment Ohridski" Research Science Fund project N80-10-75/12.04.2019 "Use of high performance computing technological tools for competence development for applying the inquiry-based approach in STEM education at secondary school". 


\section{References}

Council of the European Union (2018). Council Recommendation of 22 May 2018 on key competences for lifelong learning. Official Journal of the European Union, 2018/C 189/01, 4.6.2018. Available at: https://eur-lex.europa.eu/legalcontent/EN/TXT/?uri=uriserv:OJ.C_.2018.189.01.0001.01.ENG\&toc=OJ:C:2018:189:TOC

Enhancing Learning in Teaching via e-inquiries (ELITe) project. Retrieved from http://www.learning-in-teaching.eu

European Commission (2019). Key competences for lifelong learning. (C) European Union, 2019, PDF Version: ISBN 978-92-76-00476-9; doi:10.2766/569540; NC-02-19-150-EN-N. Available online at: https://publications.europa.eu/en/publication-detail//publication/297a33c8-a1f3-11e9-9d0101aa75ed71a1/language-en

Ministry of Education and Science, Republic of Bulgaria. (2015). Ordinance \#5 on general education. Retrieved April 10, 2017, from http://www.mon.bg/?h=downloadFile\&fileId=8661

Ministry of Education and Science, Republic of Bulgaria. (2016a). Ordinance on National requirements for acquiring professional qualification "teacher". Retrieved April 20, 2017, from http://www.mon.bg/?h=downloadFile\&fileId=10486

Ministry of Educaton and Science, Republic of Bulgaria. (2016b). Ordinance \#12 from 01 of September 2016 on the status and professional development of teachers, headmasters and other pedagogical specialists. Retrieved April 21, 2017, from Republic of Bulgaria, Ministry of Education and Science: http://www.mon.bg/?h=downloadFile\&fileId=10269

Muller, M. J., \& Kuhn, S. (1993). Special issue on participatory design. Communications of the ACM, 36(6), 24-28.

Nikolova, N., Mihnev, P., Zafirova-Malcheva, T., Stefanova, E., \& Stefanov, K. (2018). Review of Policy Envisions and Requirements for STEM Teachers in Bulgaria. Serdica Journal of Computing, 11(3-4), 279-296.

Nikolova, N., Stefanova, E., Stefanov, K., \& Mihnev, P. (2018). STEM Teachers' Competence Development: When Opportunities Jump over Barriers. In CSEDU (1) (pp. 328-335).

Nikolova, N., Stefanova, E. (2019). Open-air lessons - myth or not..., In proceedings of EDULEARN19 (pp. 1098-1106).

Peltekova, E., Stefanova, E., \& Nikolova, N. (2019, June). Space Safari: Challenge for STEM Rangers. In Proceedings of the 20th International Conference on Computer Systems and Technologies (pp. 292-298). ACM.

Sanders, E. B. N., Brandt, E., \& Binder, T. (2010, November). A framework for organizing the tools and techniques of participatory design. In Proceedings of the 11th biennial participatory design conference (pp. 195-198). ACM.

Schuler, D., \& Namioka, A. (Eds.). (1993). Participatory design: Principles and practices. CRC Press.

Stefanova, E., \& Nikolova, N. (2019). Overcoming the barriers in teacher-parent communication, In proceedings of EDULEARN19 (pp. 1107-111).

Stefanova E., Antonova A., Miteva D. \& Nikolova N., (2019) In the Dinosaur' Steps through IBL Scenario: A Way to Overcome Prejudice for Career in STEM," in CSEDU2019, Proceedings of the 11th International Conference on Computer Supported Education, 2019.

Tuxworth, E. (2005). Competence based education and training: background and origins. In Competency based education and training (pp. 18-31). Routledge.

Twyman, J. S. (2014). Competency-Based Education: Supporting Personalized Learning. Connect: Making Learning Personal. Center on Innovations in Learning, Temple University.

Voorhees, R. A. (2001). Competency - Based learning models: A necessary future. New directions for institutional research, 2001(110), 5-13. 